\title{
Differences in Hypertrophic Scar Fibroblasts according to Scar Severity: Expression of Transforming Growth Factor $\beta 1$ at the mRNA and Protein Levels
}

\author{
Se Young Kim, Seung Min Nam, \\ Eun Soo Park, Yong Bae Kim \\ Department of Plastic and Reconstructive \\ Surgery, College of Medicine, \\ Soonchunhyang University, Bucheon, \\ Korea
}

This work was supported by the Soonchunhyang University Research Fund.

No potential conflict of interest relevant to this article was reported.
Background Hypertrophic scars result from excessive collagen deposition and increased transforming growth factor beta-1 (TGF- $\beta 1$ ) levels. We hypothesized that the expression of TCF- $\beta 1$ mRNA and protein would increase with the clinical severity of hypertrophic scars.

Methods Primary dermal fibroblasts were isolated from cultures of normal skin and hypertrophic scars. The hypertrophic scars were classified by grade based on the Vancouver Scar Scale. After 96 hours of serum starvation, TGF- $\beta 1$ levels in the supernatant were determined using solid-phase, enzyme-linked immunosorbent assay (ELISA). Quantitative reverse transcription-polymerase chain reaction was performed to quantify TGF- $\beta 1$ mRNA expression.

Results TGF- $\beta 1$ protein levels of hypertrophic scars tended to increase with increasing severity of the scars, according to the Vancouver Scar Scale. The differences between the normal dermal tissue (NS), hypertrophic scar grade (HS) 1, and HS4 groups were statistically significant $(P<0.01)$. The TGF- $\beta 1$ mRNA levels of hypertrophic scars also tended to increase according to scar severity. The differences between the NS, HS1, $\mathrm{HS} 2, \mathrm{HS} 3$, and HS4 groups were statistically significant $(\mathrm{P}<0.01)$.

Conclusions The classification of hypertrophic scars according to the Vancouver Scar Scale usually matches the severity of the microenvironment of the hypertrophic scar.

Keywords Hypertrophic scar, Transforming growth factor-beta, Vancouver scar scale

\section{INTRODUCTION}

The wound-healing process involves four cascades: hemostasis, inflammation, proliferation, and remodeling. These cascades are regulated by numerous feedback and feedforward regulatory loops driven by signals from the wound microenvironment. Normal wound healing activates stop signals when a wound is closed and epithelialization is complete [1]. When these stop signals are inac-

Received: Aug 12, 2015 Revised: Sep 1, 2015 Accepted: Sep 3, 2015 Correspondence: Seung Min Nam Department of Plastic and Reconstructive, Soonchunhyang University Bucheon Hospital, 170 Jomaruro, Wonmi-gu, Bucheon 14584, Korea. E-mail: zodiac1003@naver.com

Copyright @ 2015 The Korean Society for Aesthetic Plastic Surgery.

This is an Open Access article distributed under the terms of the Creative Commons Attribution Non-Commercial License (http://creativecommons.org/licenses/by-nc/3.0/) which permits unrestricted non-commercial use, distribution, and reproduction in any medium, provided the original work is properly cited. www.e-aaps.org tive, the wound-healing process continues, causing excessive scar formation.

Hypertrophic scars and keloids are unique to humans and do not occur in animals for unknown reasons [1]. A hypertrophic scar is a fibroproliferative disorder characterized by raised, red, nodular, inelastic scars that undergo slow, incomplete regression compared to normal scars [2]. They are caused by excessive collagen synthesis and deposition from fibroblasts. Cytokines are important regulators of wound healing and scar formation [2].

Transforming growth factor beta-1 (TGF- $\beta 1$ ) is a multifunctional cytokine produced by a numerous cell types [3]. TGF- $\beta$ plays an important role in the regulation of cellular growth, differentiation, adhesion, and apoptosis [4-6]. TGF- $\beta$ stimulates skin fibroblasts to increase the production of extracellular matrix (ECM), including collagen, fibronectin, and proteoglycan, and to decrease the production of matrix-degrading proteases. As a result, TGF- $\beta$ simultaneously provokes the deposition of the ECM $[4,6]$. TGF- $\beta 1$ is the 
most fibrogenic isoform of this growth factor [7].

We hypothesized that the expression of TGF- $\beta 1$ mRNA and protein by fibroblasts is proportional to the clinical severity of hypertrophic scars. We classified hypertrophic scars into four grades, according to the Vancouver Scar Scale [8]: grade 1 scars were defined as mildly elevated $(<2 \mathrm{~mm})$, pink, and yielding hypertrophic scars; grade 2 scars were defined as moderately elevated $(2-5 \mathrm{~mm})$, red, and yielding hypertrophic scars; grade 3 scars were defined as moderately elevated $(2-5 \mathrm{~mm})$, red, and firm hypertrophic scars; and grade 4 scars were defined as severely elevated ( $>5 \mathrm{~mm}$ ), purple, and firm hypertrophic scars. To verify this hypothesis, we measured the production of TGF- $\beta 1$ protein and mRNA levels from normal human skin fibroblasts and four grades of hypertrophic scars using an in vitro serum-free culture system.

\section{METHODS}

\section{Culturing normal dermal tissue and hypertrophic scar fibroblasts}

Normal dermal tissue (NS) was obtained from six patients who underwent performed blepharoplasty. Hypertrophic scar tissues were obtained from six patients having all scar grades (HS1, HS2, HS3, and HS4). This study was approved by the institutional review board of Soonchunhyang University, Bucheon Hospital (SCHBC_ IRB_2013-39).

The tissue samples were minced into 0.5 to $1 \mathrm{~mm}^{3}$ fragments on a clean bench and washed in phosphate-buffered saline containing $100 \mathrm{U} / \mathrm{L}$ penicillin and $100 \mathrm{mg} / \mathrm{L}$ streptomycin. Then, $700 \mu \mathrm{L}$ Dulbecco's modified Eagle's medium (DMEM) supplemented with $20 \%$ fetal bovine serum (FBS) were placed in six-well cell culture flasks, and each well was plated with three to five fragments. After 4 hours, the culture medium was added. The flasks were incubated at $37^{\circ} \mathrm{C}$ under $5 \% \mathrm{CO}_{2}$ for 24 hours. The minced fragments were removed, and the DMEM was changed every 2 days. The flasks were examined daily by light microscopy for fibroblast outgrowth. When the fibroblast outgrowth approached confluence, subculturing $(3,500$ $\mathrm{cell} / \mathrm{cm}^{2}$ ) was performed. In the passage 1 subculture, the culture medium was changed to DMEM containing $15 \%$ FBS; in the passage 2 subculture, the culture medium was changed to DMEM containing 10\% FBS.

Subculturing was performed after the fibroblasts had spread on the bottom of the cell culture flask. The fibroblasts were used at passage 4 . The fibroblasts were released from the culture flask using $0.05 \%$ trypsin. After confirming cellular release from the flask wall by light microscopy, trypsin soybean inhibitor was added to each flask in a 1:1 ratio to inactivate the trypsin. The fibroblasts were subcultured into six-well cell culture flasks at a density of 1.5 $\times 10^{5}$ cells per well in DMEM containing $10 \% \mathrm{FBS}$. After 24 hours, the medium was replaced with DMEM containing $2 \%$ FBS. The flasks were incubated at $37^{\circ} \mathrm{C}$ under $5 \% \mathrm{CO}_{2}$ for 96 hours.
Quantitative-competitive ELISA for TGF- $\beta 1$

First, $1 \mathrm{~mL}$ medium was harvested from each well and centrifuged for 20 minutes at $1,000 \times \mathrm{g}$ at $4^{\circ} \mathrm{C}$. The cell-free supernatant was evaluated using a solid-phase, enzyme-linked immunosorbent assay (ELISA) using the Quantikine ELISA kit for TGF- $\beta 1$ (R\&D Systems, Minneapolis, MN, USA). The optical densities of the samples were determined using an automated plate reader.

Total RNA isolation from fibroblasts using TRIzol Fibroblasts $\left(1 \times 10^{6}\right)$ were combined with $1 \mathrm{~mL}$ TRIzol (Invitrogen, Carlsbad, CA, USA) reagent and homogenized. The homogenate was allowed to stand for 5 minutes. Then, $200 \mu \mathrm{L}$ chloroform (per 1 $\mathrm{mL}$ TRIzol) were added, and the mixture was shaken vigorously for 15 seconds. The sample was allowed to stand for 3 minutes at room temperature and centrifuged at $12,000 \times \mathrm{g}$ at $4^{\circ} \mathrm{C}$ for $15 \mathrm{~min}$ utes. The colorless, upper aqueous phase was transferred to a diethylpyrocarbonate (DEPC)-treated Eppendorf centrifuge (EP) tube. Next, $500 \mu \mathrm{L}$ of $100 \%$ isopropanol and $1 \mathrm{~mL}$ TRIzol were added to the aqueous phase and inverted 30 times. After incubating for 10 minutes at room temperature, the mixture was centrifuged for 10 minutes at $12,000 \times \mathrm{g}$ at $4^{\circ} \mathrm{C}$. The isopropanol layer was decanted, and the RNA pellet was washed with $1 \mathrm{~mL}$ cold $75 \%$ DEPC-treated water/ethyl alcohol. The samples were centrifuged for 5 minutes at 7,500 $\times \mathrm{g}$ at $4^{\circ} \mathrm{C}$, and the supernatant was decanted carefully. The pellet was allowed to air dry for 5 to 10 minutes at room temperature under a laminar flow hood without over drying. Then, $20 \mu \mathrm{L}$ DEPC-treated $\mathrm{H}_{2} \mathrm{O}$ were added to the dried pellet and mixed with a pipette tip on ice. The RNA samples were warmed to 55 to $65^{\circ} \mathrm{C}$ in a heating block for 10 to 15 minutes. To assess the quantity and purity of the RNA, the optical density of the total RNA (diluted 1:100 with DEPC-treated $\mathrm{H}_{2} \mathrm{O}$ ) was determined by spectrophotometry.

\section{Quantitative reverse transcription-polymerase chain reaction (RT-PCR)}

Purified total RNA was reverse-transcribed to first-strand cDNA using oligo-(dT) with a SuperScript II First Strand Synthesis System (Invitrogen Life Technologies, Carlsbad, CA, USA), according to the manufacturer's recommendations. The specific primer pairs for RT-PCR were as follows: Beta-actin forward, $5^{\prime}$-CATGTACGTT GCTATCCAGGC-3'; Beta-actin reverse, 5'-CTCTTAATGTCACG CACGAT-3'; TGF- $\beta 1$ forward, $5^{\prime}$-CTAATGGTGGAAACCCACA ACG-3'; and TGF- $\beta 1$ reverse, $5^{\prime}$-TATCGCCAGGAATTGTTGC TG-3'.

Amplification consisted of an initial denaturation at $94^{\circ} \mathrm{C}$ for 5 minutes, followed by 35 cycles of 30 seconds at $94^{\circ} \mathrm{C}, 30$ seconds at $55^{\circ} \mathrm{C}$, and 40 seconds at $72^{\circ} \mathrm{C}$, and a final extension at $72^{\circ} \mathrm{C}$ for 10 minutes. The size and amount of the PCR products generated were determined by agarose gel electrophoresis in the presence of ethidium bromide and analyzed with by Kodak EDAS 1D software (Ko- 
Table 1. The TGF-B1 protein levels of the cell lines were determined using ELISA

\begin{tabular}{lcccccc}
\hline Fibroblasts & NS & HS1 & HS2 & HS3 & HS4 & P-value \\
\hline TGF-B1 & $513.38^{\text {al }} \pm 13.53$ & $643.31^{\text {al }} \pm 12.5$ & $719.60 \pm 6.43$ & $729.43 \pm 3.11$ & $746.07^{\text {al }} \pm 5.86$ & 0.000 \\
\hline
\end{tabular}

Mean \pm standard deviation (SD). P-value by one-way analysis of variance (or ANOVA).

alSame letters indicate significantly difference based on Turkey's multiple comparison.

NS, normal dermal tissue; HS1, hypertrophic scar grade 1; HS2, hypertrophic scar grade 2; HS3, hypertrophic scar grade 3; HS4, hypertrophic scar grade 4; TGFB1, transforming growth factor beta-1; ELISA, enzyme-linked immunosorbent assay.

Table 2. TGF-B1 mRNA levels were quantified and compared by RT-PCR

\begin{tabular}{|c|c|c|c|c|c|c|}
\hline Fibroblasts & NS & HS1 & HS2 & HS3 & HS4 & $\mathrm{P}$-value** \\
\hline TGF-B1 mRNA* & $0.71^{\mathrm{al}} \pm 0.01$ & $0.92^{\mathrm{al}} \pm 0.01$ & $0.98^{\mathrm{al}} \pm 0.01$ & $1.07^{\mathrm{al}} \pm 0.02$ & $1.24^{\mathrm{al}} \pm 0.04$ & 0.000 \\
\hline
\end{tabular}

*Mean $\pm \mathrm{SD}$; **P-value by one-way analysis of variance (or ANOVA).

a) Same letters indicate significantly difference based on Turkey's multiple comparison.

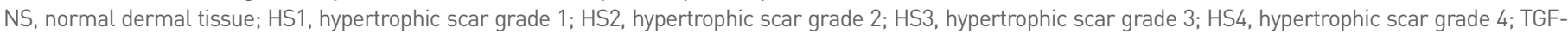
$B 1$, transforming growth factor beta-1; RT-PCR, reverse transcription-polymerase chain reaction.

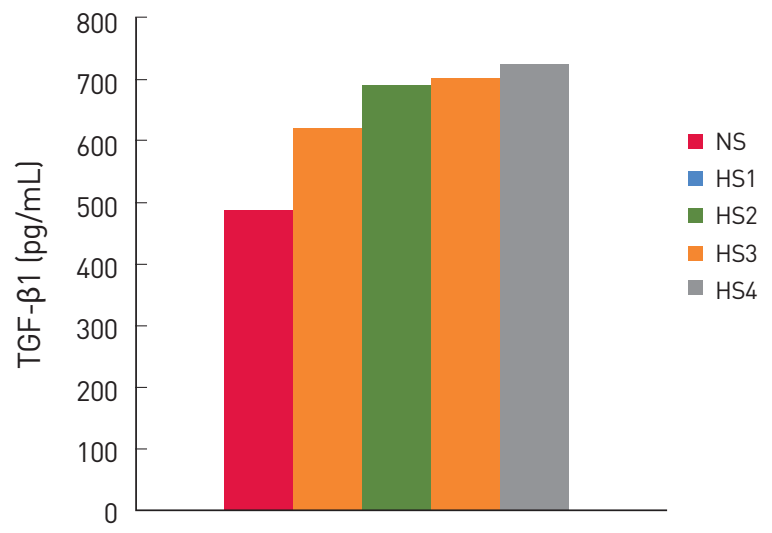

Fig. 1. ELISA-determined TGF-B1 protein levels in the supernatants of cultures of hypertrophic scar and normal dermal fibroblasts. ELISA, enzyme-linked immunosorbent assay; TGF-B1, transforming growth factor beta-1.

dak, New Haven, CT, USA). The RT-PCR products were identified by a BLAST search after direct sequencing.

\section{Statistical analysis}

A one-way analysis of variance (ANOVA) was used to compare groups, and $\mathrm{P}$ less than 0.05 was considered statistically significant (SPSS ver. 18.0; SPSS Inc., Chicago, IL, USA).

\section{RESULTS}

TGF- $\beta 1$ protein levels of the cell lines were determined using ELISA. Six pairs of HS1, HS2, HS3, HS4, and NS samples were examined (Table 1). Overall, normal dermal fibroblasts produced 518.38 $\pm 13.53 \mathrm{pg}$ TGF- $\beta 1$ protein $/ \mathrm{mL}$. The grade 1 to 4 hypertrophic scar fibroblasts produced $643.31 \pm 12.5,719.60 \pm 6.43,729.43 \pm 3.11$, and $746.07 \pm 5.86$ pg TGF- $\beta 1$ protein/mL (Fig. 1). The differences be-
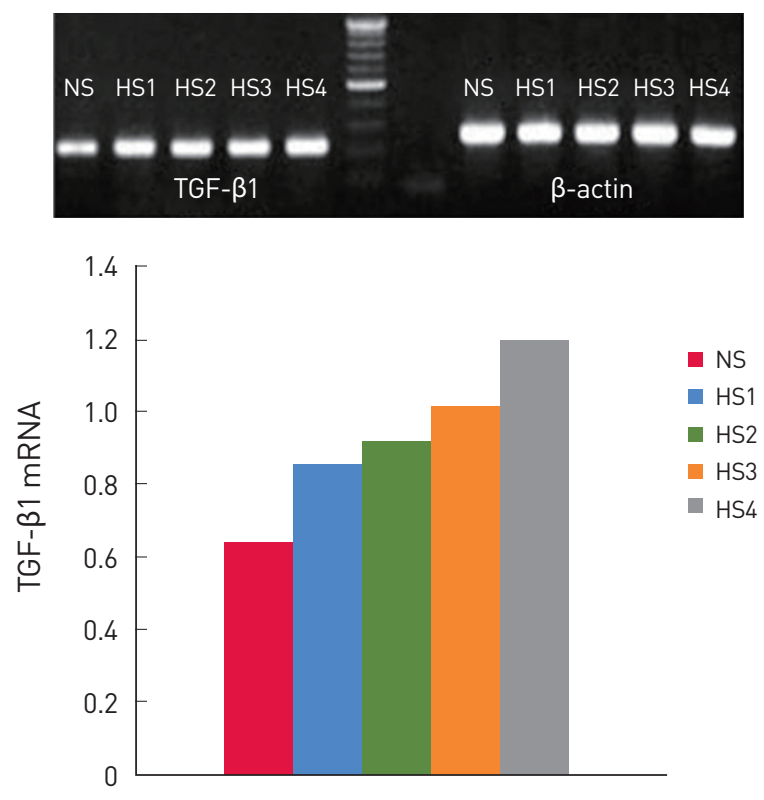

Fig. 2. TGF-B1 mRNA expression in hypertrophic scar and normal dermal fibroblasts was determined by RT-PCR. TGF-B1, transforming growth factor beta-1; RT-PCR, reverse transcription-polymerase chain reaction.

tween the NS, HS1, and HS4 groups were statistically significant $(\mathrm{P}<0.01)$.

Relative TGF- $\beta 1$ mRNA levels were quantified and compared by RT-PCR in six pairs of hypertrophic scar and normal fibroblast lines (Table 2). The normal dermal fibroblasts expressed $0.71 \pm 0.01$ (TGF- $\beta 1 / \beta$-actin) TGF- $\beta 1$ mRNA.

Grade 1 to 4 hypertrophic scar fibroblasts expressed $0.92 \pm 0.01$, $0.98 \pm 0.01,1.07 \pm 0.02$, and $1.24 \pm 0.04$ TGF- $\beta 1 \mathrm{mRNA}$ (Fig. 2). The differences between the NS, HS1, HS2, HS3, and HS4 groups were statistically significant $(\mathrm{P}<0.01)$. 


\section{DISCUSSION}

Dermal fibroblasts facilitate wound healing by migrating to the wound, forming granulation tissue, and synthesizing ECM components [9]. Moreover, they generate the mechanical force that initiates wound contraction [10], which contributes to wound healing by decreasing the wound area and forming a scar [11]. However, undesirable wound contraction can lead to cosmetic and functional problems [12-14].

A hypertrophic scar is a common complication of wound healing in patients who had thermal and other dermal injuries [15]. It involves the abnormal proliferation of fibroblasts and overproduction of collagen and ECM $[15,16]$. Hypertrophic scar formation is regulated by the activity of TGF- $\beta$ [15].

TGF- $\beta 1$ plays a vital role in the pathogenesis of hypertrophic scar formation $[11,17]$. Hypertrophic scar fibroblasts produce more TGF- $\beta 1$ protein and mRNA than do normal dermal fibroblasts $[2,11]$. TGF- $\beta 1$ induces fibroblast proliferation and the synthesis of ECM components, such as elastin, fibronectin, and collagen [1719]. In vitro, TGF- $\beta 1$ reduces the collagenase-mediated degradation of the wound matrix and indirectly stimulates matrix growth by inducing platelet-derived growth factor [17,20,21]. TGF- $\beta 1$ enhances the contraction of collagen gel and thus of the wound itself [22-24]. An important role of TGF is underpinned by the fact that neutralizing antibodies to TGF inhibit hypertrophic scar formation [17,25-27].

We compared TGF- $\beta 1$ protein and mRNA levels in normal and hypertrophic scar dermal fibroblasts. The hypertrophic scar dermal fibroblasts were divided into four groups based on the Vancouver Scar Scale. Production of TGF- $\beta 1$ protein by normal and hypertrophic scar dermal fibroblasts differed significantly. There were statistically significant differences among the NS, HS1, and HS4 groups. Although the TGF- $\beta 1$ protein of the HS2 and HS3 groups tended to increase with the clinical severity of the hypertrophic scars, there was no significant difference between the HS2 and HS3 groups.

TGF- $\beta 1$ mRNA expression also differed significantly between normal and hypertrophic scar dermal fibroblasts. There were statistically significant differences among the NS, HS1, HS2, HS3, and HS4 groups.

We hypothesized that the production of TGF- $\beta 1$ protein and mRNA would increase with the Vancouver Scar Scale of hypertrophic scarring. The production of TGF- $\beta 1$ tended to increase with the Vancouver Scar Scale, and the differences were significant, except for groups HS2 and HS3. Regarding TGF- $\beta 1$ mRNA expression, the differences between the HS1, HS2, HS3, and HS4 groups were statistically significant, which can be attributed to the inherent variability in TGF- $\beta 1$ expression in our hypertrophic scar dermal fibroblast lines, possibly correlating with the clinical heterogeneity of the hypertrophic scars. That is, the TGF- $\beta 1$ protein levels of a hypertrophic scar may not necessarily match its RNA levels.

Our study has two limitations. One is that the hypertrophic scar tissues that we studied each had different scar maturation times. The other limitation is that the hypertrophic scar grades are subjective criteria. However, despite these limitations, we can conclude that the classification of hypertrophic scars using the Vancouver Scar Scale usually reflects the microenvironment of hypertrophic scar formation.

\section{REFERENCES}

1. Mirastschijski U, Jokuszies A, Vogt PM. Skin wound healing: repair biology, wound, and scar treatment. In: Neligan PC, editor. Plastic surgery. London, UK: Elsevier Inc; 2013. p. 267-96.

2. Wang R, Ghahary A, Shen Q, et al. Hypertrophic scar tissues and fibroblasts produce more transforming growth factor-beta1 mRNA and protein than normal skin and cells. Wound Repair Regen 2000;8:12837.

3. Roberts AB, Flanders KC, Heine UI, et al. Transforming growth factor-beta: multifunctional regulator of differentiation and development. Philos Trans R Soc Lond B Biol Sci 1990;327:145-54.

4. Border WA, Noble NA. Transforming growth factor beta in tissue fibrosis. N Engl J Med 1994;331:1286-92.

5. Massagué J. The transforming growth factor-beta family. Annu Rev Cell Biol 1990;6:597-641.

6. Miyazono K, ten Dijke P, Heldin CH. TGF-beta signaling by Smad proteins. Adv Immunol 2000;75:115-57.

7. Robson MC. The role of growth factors in the healing of chronic wounds. Wound Repair Regen 1997;5:12-7.

8. Sullivan T, Smith J, Kermode J, et al. Rating the burn scar. J Burn Care Rehabil 1990;11:256-60.

9. Grinnell F. Fibroblasts, myofibroblasts, and wound contraction. J Cell Biol 1994;124:401-4.

10. Gabbiani G, Hirschel BJ, Ryan GB, et al. Granulation tissue as a contractile organ. A study of structure and function. J Exp Med 1972;135: 719-34.

11. Zhang Z, Garron TM, Li XJ, et al. Recombinant human decorin inhibits TGF-beta1-induced contraction of collagen lattice by hypertrophic scar fibroblasts. Burns 2009;35:527-37.

12. Brissett AE, Sherris DA. Scar contractures, hypertrophic scars, and keloids. Facial Plast Surg 2001;17:263-72.

13. Fang $\mathrm{CH}$, Alexander JW. Wound contraction following transplantation of microskin autografts with overlaid skin allograft in experimental animals. Burns 1990;16:190-2.

14. Vande Berg JS, Rudolph R. Cultured myofibroblasts: a useful model to study wound contraction and pathological contracture. Ann Plast Surg 1985;14:111-20.

15. Zhang Z, Li XJ, Liu Y, et al. Recombinant human decorin inhibits cell proliferation and downregulates TGF-beta1 production in hypertrophic scar fibroblasts. Burns 2007;33:634-41. 
16. Su CW, Alizadeh K, Boddie A, et al. The problem scar. Clin Plast Surg 1998;25:451-65.

17. Niessen FB, Spauwen PH, Schalkwijk J, et al. On the nature of hypertrophic scars and keloids: a review. Plast Reconstr Surg 1999;104:143558.

18. Rodland KD, Muldoon LL, Magun BE. Cellular mechanisms of TGFbeta action. J Invest Dermatol 1990;94:33s-40s.

19. Zhang K, Garner W, Cohen L, et al. Increased types I and III collagen and transforming growth factor-beta $1 \mathrm{mRNA}$ and protein in hypertrophic burn scar. J Invest Dermatol 1995;104:750-4.

20. Leof EB, Proper JA, Goustin AS, et al. Induction of c-sis mRNA and activity similar to platelet-derived growth factor by transforming growth factor beta: a proposed model for indirect mitogenesis involving autocrine activity. Proc Natl Acad Sci U S A 1986;83:2453-7.

21. Overall CM, Wrana JL, Sodek J. Transforming growth factor-beta regulation of collagenase, $72 \mathrm{kDa}$-progelatinase, TIMP and PAI-1 expression in rat bone cell populations and human fibroblasts. Connect Tissue Res 1989;20:289-94.
22. Finesmith TH, Broadley KN, Davidson JM. Fibroblasts from wounds of different stages of repair vary in their ability to contract a collagen gel in response to growth factors. J Cell Physiol 1990;144:99-107.

23. Tateshita T, Ono I, Kaneko F. Effects of collagen matrix containing transforming growth factor (TGF)-beta(1) on wound contraction. J Dermatol Sci 2001;27:104-13.

24. Montesano R, Orci L. Transforming growth factor beta stimulates collagen-matrix contraction by fibroblasts: implications for wound healing. Proc Natl Acad Sci U S A 1988;85:4894-7.

25. Shah M, Foreman DM, Ferguson MW. Neutralising antibody to TGFbeta 1,2 reduces cutaneous scarring in adult rodents. J Cell Sci 1994; 107:1137-57.

26. Shah M, Foreman DM, Ferguson MW. Control of scarring in adult wounds by neutralising antibody to transforming growth factor beta. Lancet 1992;339:213-4.

27. Shah M, Foreman DM, Ferguson MW. Neutralisation of TGF-beta 1 and TGF-beta 2 or exogenous addition of TGF-beta 3 to cutaneous rat wounds reduces scarring. J Cell Sci 1995;108:985-1002. 